\title{
Improving the Performance of Sequencing Batch Biofilm Reactor (Sbbr) by Additing the Zeolite Powder
}

\author{
Yun Xia Wei, Ming Guang Ma, Guo Hu Zhao, Shi Hong Xu, Fang Liu \\ School of Chemistry and Environmental Science, Lan zhou City University, Lan Zhou, China
}

Email address:

weiyx07@1zu.edu.cn (Yun Xia Wei)

\section{Tocite this article:}

Yun Xia Wei, Ming Guang Ma, Guo Hu Zhao, Shi Hong Xu, Fang Liu. Improving the Performance of Sequencing Batch Biofilm Reactor (Sbbr) by Additing the Zeolite Powder. Journal of Health and Environmental Research. Vol. 2, No. 6, 2016, pp. 34-38. doi: $10.11648 /$ j.jher.20160206.11

Received: July 26, 2016; Accepted: August 29, 2016; Published: December 30, 2016

\begin{abstract}
Two types of operation means "SBBR reactor alone (Sreactor)" and "adding zeolite powder into SBBR reactor (Z-Sreactor)" were used to treat municipal wastewater. The test results showed that zeolite added in reactor could improve the activity of the activated sludge. Due to the combination of zeolite adsorption for $\mathrm{NH}_{4}{ }^{+} \mathrm{N}$ enhanced simultaneous nitrification andde-nitrification (SND), a higher nitrogen removal was observed in Z-S reactor compared to the S reactor, and the addition of zeolite powder is helpful to inhabit sludge bulking. Inaddition, through long-term parallel shock load test, it was found that the zeolite added in reactor could enhance the ability of activated sludge inresisting the shock load of organics and ammonium.
\end{abstract}

Keywords: Sequencing Batch Biofilm Reactor (SBBR), Zeolite Powder, Adsorption, Ammonia Nitrogen, Municipal Wastewater

\section{Introduction}

Ammoniacal nitrogen present in effluent sarising from the treatment of municipal wastewater can promote eutrophication in receiving waters and increase toxicity to aquatic life [1-4]. Hence, the removal of ammonium from wastewater is of great importance in the control of nitrogen pollution [2].

The need for cost-effective wastewater treatment technology is becoming increasingly important. To achieve a higher effluent quality without an increase in operational costs, an increased understanding of the controlling factors of nitrogen removal is necessary. In wastewater treatment processes designed for nitrogen removal, the cost of aeration can amount to $50 \%$ of the total electrical power consumption of the plant [5]. Thus, any decrease in the amount of oxygen required to achieve nitrogen removal represents economical savings. In the last decade it has become clear that, if the oxygen concentration is carefully controlled, both nitrification and denitrification can occur under identical operating conditions by simultaneous nitrification and denitrification (SND) $[6,7]$. SND is an attractive alternative technology for N-removal due to its potential to eliminate the need for separate tanks as required in conventional treatment plants, resulting in a simplified and smaller plant design $[8,9]$.

The naturally occurring zeolite, clinoptilolite, is a potential adsorbent of ions because of its high capacity and low cost. Structurally, clinoptilolite consists of a frame work of alumino silicates based on an infinite three-dimensional structure of $\mathrm{SiO}_{4}$ and $\mathrm{AlO}_{4}$ tetrahedra molecules linked to each other by shared oxygen [10]. These adsorbent materials have, in their internal structure, channels and cavities interconnected by molecular dimensions where there are compensation cations allowing ion exchange.

Many authors have studied the use of natural zeolites in environmental applications mainly to remove ions from wastewater by adsorption ionic exchange processes [11]. Simple ion exchange technology can usually be used as a pretreatment method, but it has rarely been tested for wastewater with a high ammonium nitrogen content due to the chemical regeneration cost of the used zeolite [12].

Biological wastewater treatment processes are classified as either attached growth or suspended growth [13-15]. In attached growth process, an active thin layer of microorganisms known as biofilm is developed on the solidsupport. Organic matter, nutrients and oxygen diffuse into the biofilm where they are consumed and reacted by the living microorganisms, while the products diffuse out from 
the biofilm. Attached growth processes seem to be more stable than suspended growth processes, especially important when the wastewater has considerable fluctuations in flow rate and concentrations [16].

Based on this idea, this study was conducted to compared is crepancies in operation efficiency when powdered zeolite was directly added into SBR. The effects of powdered zeolite carrier on nitrification in the SBR under organics and nitrogen shock loading were tested. In this study, two SBRs were run in parallel to treat municipal wastewater, of which one was fed with a certain quantity of natural zeolite powder while the other was run as control system, and the aim of the study was to investigate the effect of zeolite powder addition on the performance of SBBR in treating municipal wastewater.

\section{Materials and Methods}

A natural zeolite sample used in the experiments was provided by Baiyin (Gansu Province, China), then the zeolite was ground to powder form, its main characteristics were as follows: particle size $\backslash 0.25 \mathrm{~mm}$; true density $=2.15 \mathrm{~g} / \mathrm{ml}$; surface area $=45.3 \mathrm{~m}^{2} / \mathrm{g}$; pore size $=5 \mathrm{~nm}$.

The natural zeolite was washed repeatedly with $1 \mathrm{M} \mathrm{HCl}$ solution and $1 \mathrm{M} \mathrm{NaOH}$ solution, the wet pre-treatment material was dried at $100^{\circ} \mathrm{C}$, for $10 \mathrm{~h}$, and used in the modification stage.

Composite polyurethane foam material was prepared according to the method described in our previous work [17]. The resulting composite polyurethane foam was cut into cubes $(1.0 \mathrm{~cm} \times 1.0 \mathrm{~cm} \times 1.0 \mathrm{~cm})$. The cubes were alternately eluted by $5 \% \mathrm{NaOH}$ solution and $5 \% \mathrm{HCl}$ to remove the soluble small molecule, then were washed with distilled water until the $\mathrm{pH} 7.0$ and finally dried at $60^{\circ} \mathrm{C}$ under vacuum. The dried cubes were then used as carrier materials.

Seed sludge was inoculated from Lan zhou wastewater treatment plant. The composition of the synthetic wastewater was glucose $150 \mathrm{mg} / 1, \mathrm{NH}_{4} \mathrm{Cl} 125 \mathrm{mg} / \mathrm{l}, \mathrm{NaHCO}_{3} 200 \mathrm{mg} / \mathrm{l}$, $\mathrm{KH}_{2} \mathrm{PO}_{4} 66 \mathrm{mg} / \mathrm{l}$, and other trace elements (Fe, Mn, Ca, Mg).

The zeolite powder was added into the test reactor 15 days priortothesteadystate. Batch zeolite powder addition was applied to compensate for the loss of zeolite powder through sludge wastage to maintain zeolite powder at $1.0 \mathrm{~g} / \mathrm{l}$ throughout the test cycle, and the addition of zeolite powder into test reactor was conducted between fill and aeration stage of every cycle.

A lab-scale sequencing batch reactores sentially consisted of a Plexiglass cylindrical vessel of $12 \mathrm{~cm}$ diameter and $30 \mathrm{~cm}$ height, filled with biomass support material togive $8 \mathrm{~cm}$ according to the results obtained by Rajasimman and Karthikeyan [18], and aerated by air injection through a fine-bubble diffuser at the bottom of the reactor. The reactor was equipped with an external loop allowing wastewater recirculation via a peristaltic pump. A schematic diagram of the process configuration is shown in Figure 1.

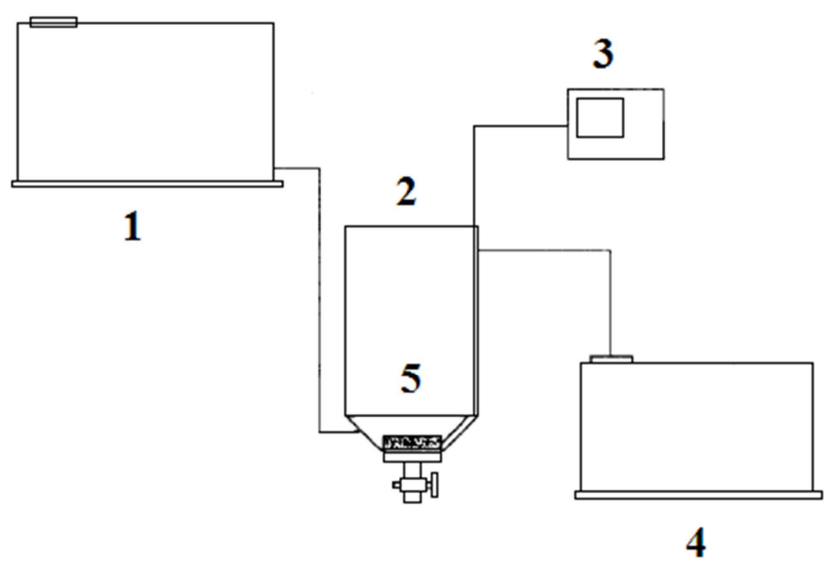

Fig. 1. Schematic illustration of the experimental system. 1 feedtank, 2 reactor, 3 thermostat, 4 storage tank, 5 airdistributor.

There were all two reactors, of which one reactor was run as control reactor (SBBR) and the other reactor was fed with zeolite powder astest reactor (Ze o-SBBR). The operating condition of the zeo-SBBR was the same as the control reactor. And the time schedule of each mode was as follows: feeding was $30 \mathrm{~min}$, aeration was $300 \mathrm{~min}$, settling was 90 min, effluent discharge was $15 \mathrm{~min}$. Two SBBRs were run for 4 weeks according to above cycle procedure, and then reached the steady state. After that, the detailed research was conducted.

For components analyses, all samples were filtered through 0.45um membranes. $\mathrm{NH}_{4}^{+}-\mathrm{N}, \mathrm{NO}_{3}^{-}-\mathrm{N}, \mathrm{NO}_{2}^{-}-\mathrm{N}$, COD, MLSS, and MLVSS were measured according to Standard Methods [19]. The $\mathrm{NH}_{4}{ }^{+}-\mathrm{N}, \mathrm{NO}_{3}{ }^{-}-\mathrm{N}$, and $\mathrm{NO}_{2}^{-}-\mathrm{N}$ were analyzed, respectively, by the HANNA HI 93715,HI 93728, and HI 93708 instrument.

\section{Results and Discussion}

\subsection{Adsorption Studies}

The contact time experiments were conducted under static conditions as the following procedure: prepare $\mathrm{NH}_{4} \mathrm{Cl}$ solution by de-ionized water; the $\mathrm{pH}$ adjustment was done using $\mathrm{HCl}$ and $\mathrm{NaOH}$ solutions. Add zeolite with accurate weight $\mathrm{M}(\mathrm{g})$ and $\mathrm{NH}_{4} \mathrm{Cl}$ solution of $\mathrm{V}(\mathrm{ml})$ into one $250 \mathrm{ml}$ flask. Seal the flask and put it on an orbital shaker. Set the rotation rate and temperature of the shaker and let the zeolite-solution system interact sufficiently; the equilibrium time was confirmed to be enough by the adsorption kinetic test previously. Adsorbed $\mathrm{NH}_{4}^{+}-\mathrm{N}$ concentration was calculated on the basis of the decrease of $\mathrm{NH}_{4}{ }^{+}-\mathrm{N}$ concentration in the solution, by means of a mass balance and assuming no variation in the solution volume. $\mathrm{The}^{\mathrm{N}}{ }_{4}{ }^{+}$ $\mathrm{N}$ concentration in the solution, both before and after contacting the support was determined. The amount of $\mathrm{NH}_{4}{ }^{+}-$ $\mathrm{N}$ adsorbed on the zeolite, $\mathrm{C}_{\mathrm{w}}(\mathrm{mg} / \mathrm{g})$, was calculated through amass balance on the basis of the different between the initial solute concentration in the solution, $\mathrm{C}_{\mathrm{i}}(\mathrm{mg} / \mathrm{ml})$, and the equilibrium or final solute concentration in the solution, $\mathrm{C}_{\mathrm{f}}(\mathrm{mg} / \mathrm{ml})$, and assuming negligible variation in the solution 
volume.The following expression was used

$$
C_{w}=\frac{\left(C_{i}-C_{f}\right) V}{M}
$$

Where $\mathrm{V}(\mathrm{ml})$ was the solution volume and $\mathrm{M}(\mathrm{g})$ was the support mass.

Langmuir and Freundlich models were employed to fit the equilibrium data (isotherm) obtained. According to the adsorption isotherms of $\mathrm{NH}_{4}{ }^{+}-\mathrm{N}$ on zeolite at different temperatures, the linear experimental isotherm constants that are obtained, either Langmuir or Freundlich, fit well the data obtained with correlation coefficient values of $r^{2}=0.9538$ and 0.8878 , respectively. Yet the Langmuir model showed better adjustment, which appears to indicate a monolayer adsorption mechanism.

The type of adsorption can be determined through thermodynamic quantities as $\triangle \mathrm{Hads}$ and $\triangle S$ [20]. The adsorption process is composed of two contributions, i.e., enthalpic and entropic, which characterize whether the reaction is spontaneous or not. From the Langmuir isotherm model, adsorption heating of $\mathrm{NH}^{4+}-\mathrm{N}$ on to zeolite can be calculated from the temperature dependence of the equilibrium adsorption constant(k) by the ClausiusClaperyon's equation.

$$
\frac{\partial \lg k}{\partial\left(\frac{1}{T}\right)}=\frac{-\Delta H_{a d s}}{2.303 R}
$$

A plot of $\log \mathrm{k}$ versus $1 / \mathrm{T}$ should be linear with slope $-\Delta \mathrm{H}$ /2.303R and with intercept $\Delta \mathrm{S} / 2.303 \mathrm{R}$. These quantities are related via

$$
-R T \ln k=\Delta G_{a d s}=\Delta H-T \Delta S
$$

Examination of the adsorption isotherms revealed that $\Delta$ Hads and $\Delta \mathrm{S}$ values calculated by the Langmuir equilibrium constants were approximately equal to $2.051 \mathrm{~J} \cdot \mathrm{mol}^{-1}, 0.01979$ $\mathrm{J} \cdot \mathrm{K}^{-1}$, when $\Delta$ Gads values were $-3.846 \mathrm{~kJ} \cdot \mathrm{mol}^{-1},-4.035$ $\mathrm{kJ} \cdot \mathrm{mol}^{-1}$, and $-4.242 \mathrm{~kJ} \cdot \mathrm{mol}^{-1}$ at 25,35 and $45^{\circ} \mathrm{C}$, respectively. The positive $\Delta \mathrm{H}$ values implied that the adsorption process was endothermic in the present system. At the three different temperatures, the $\Delta$ Hads values were lower than the limit of chemisorption of $42.0 \mathrm{~kJ} \cdot \mathrm{mol}^{-1}$, it means that the sorption of $\mathrm{NH}^{4+}-\mathrm{N}$ on zeolite was affected by physisorption rather than by chemical bonding. However, the free energy values ( $\Delta \mathrm{Gads}$ ) appeared to be very small and negative, indicating that the reaction was spontaneous.

\subsection{Mechanism and Role of the Zeolite in the SBBR}

Fig 2 shows the IR spectra of immobilized microorganisms carrier, where the carrier have four strong absorption peaks between $1000 \mathrm{~cm}-1$ and $3500-1$ corresponding to the symmetric stretching of $-\mathrm{OH}, \mathrm{C}-\mathrm{H},-\mathrm{C}=$ and $\mathrm{N}-\mathrm{H}$.

The carrier contains functional groups such as $-\mathrm{OH}$, $-\mathrm{COOH},-\mathrm{CONH}_{2}$, and $-\mathrm{NH}_{2}$, which may facilitate the micro-organism immobilization process by the linking and adsorption process between carrier and microorganism under mild conditions [21, 22]. Furthermore, the carrier that had internal aerobic and anoxic zones as well, and could immobilize micro-organism effectively, and the efficiency of simultaneous removal of carbon and nitrogenous compounds will be much higher in the same environmental conditions.

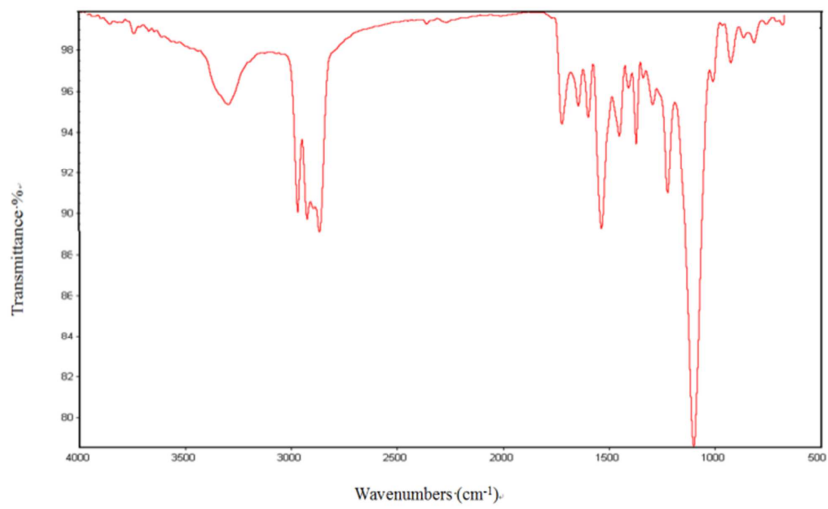

Fig. 2. FTIR transmission spectra of $P U$.

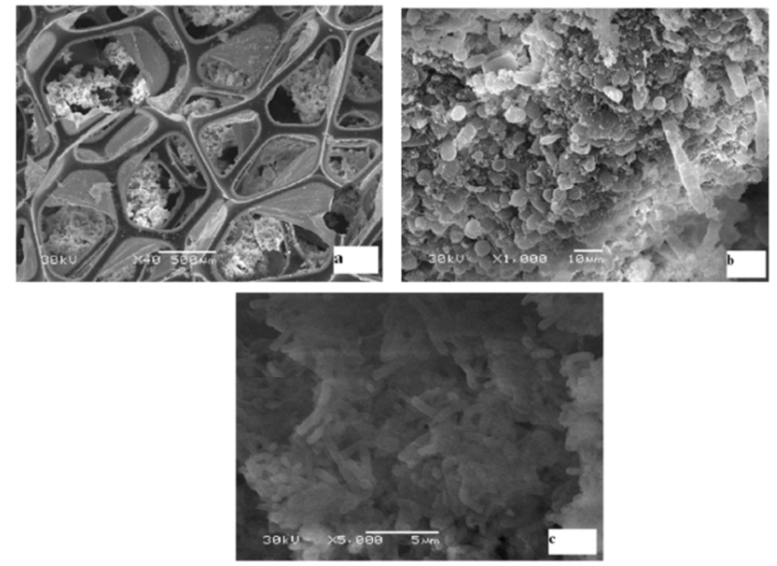

Fig. 3. SEM photos of carrier immobilized microorganisms. (a, carrier immobilized microorganism; $b$ and $c$, carrier added the powder zeolite immobilized microorganisms.

As the powdered zeolite was added into the SBBR, microorganisms that were attached on the surface of zeolite or were entrapped in the powdered zeolite particles formed zeolite-flocs, as shown by scanning electron microscopy (SEM) (Figure 3). These zeolite-flocs enhanced the settle ability of microbial floc due to the higher specific gravity of zeolite. The zeolite-flocs adsorbed ammonium nitrogen during the anoxic fill phase. At the same time, denitrification was active in this phase with biodegradable organics. The adsorbed ammonium nitrogen was released into the liquid phase due to the chemical equilibrium, and transformed to oxidized nitrogen by nitrifiers during the aeration mixing phase. Thus, zeolite-flocs can play an important role in ammonium removal in the SBBR.

\subsection{Comparison of SBBR Performance}

Time series samples were taken during steady operation for measurement of $\mathrm{NH}_{4}{ }^{+}-\mathrm{N}, \mathrm{NO}_{3}{ }^{-} \mathrm{N}, \mathrm{NO}_{2}{ }^{-} \mathrm{N}, \mathrm{TN}$, and COD 
through the course of the test.

According to Fig. 4, $\mathrm{NH}_{4}{ }^{+}-\mathrm{N}$ kept almost stable at first 40 min and then reduced to $2.4 \mathrm{mg} / \mathrm{L}$ at the next $90 \mathrm{~min}$ in SBBR reactor. For Z-S reactor, $\mathrm{NH}_{4}{ }^{+}-\mathrm{N}$ quickly reduced from 25 $\mathrm{mg} / \mathrm{L}$ to $17.8 \mathrm{mg} / \mathrm{L}$ at the first $40 \mathrm{~min}$, while the content of (nitrate + nitrite) increased was negligible at this period. Therefore, the reduction of $\mathrm{NH}_{4}{ }^{+}-\mathrm{N}$ should be attributed to the adsorption and ion exchange of zeolite powder for $\mathrm{NH}_{4}{ }^{+}-\mathrm{N}$.

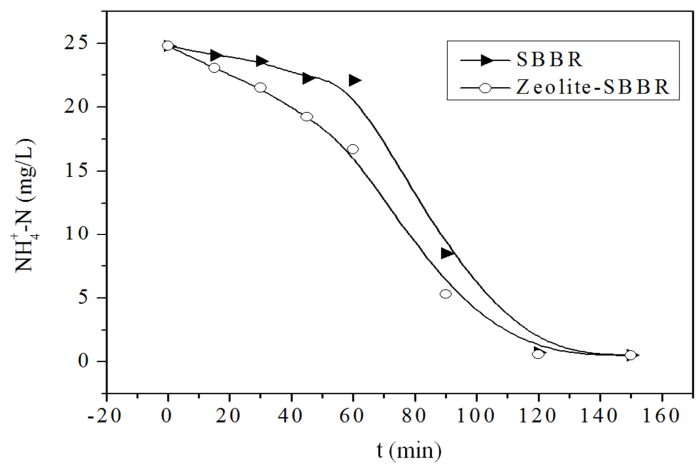

Fig. 4. Ammonium profiles for one cyclein SBBR and Zeolite-SBBR.

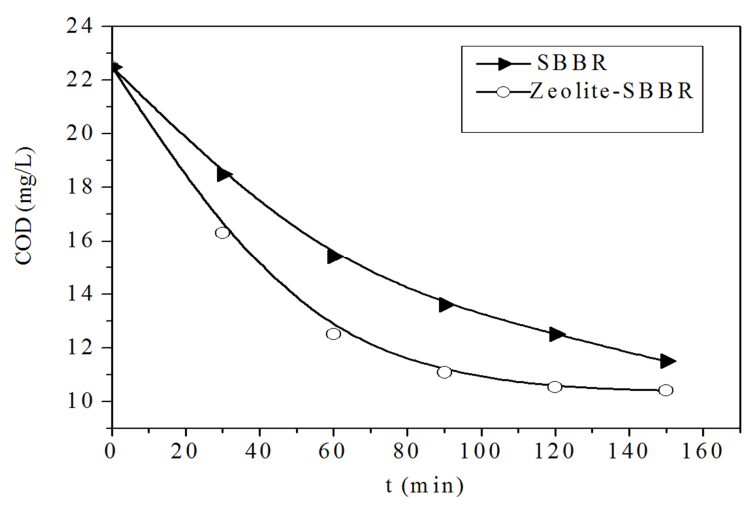

Fig. 5. COD profiles for one cycle in SBBR and Zeolite-SBBR.

According to Fig. 5, COD decreased from $22.5 \mathrm{mg} / \mathrm{L}$ to 11.5 $\mathrm{mg} / \mathrm{L}$ at a time period of $150 \mathrm{~min}$ in $\mathrm{S}$ reactor, while it last 80 min for Z-S reactor. COD reduced in a linear way at the first 40min for two SBBRs. Large quantities of COD were adsorbed and/or up taken on activated sludge in the anoxic phase. After aeration $(2.5 \mathrm{~h}), \mathrm{COD}$ in the test reactor was decomposed to a low level.

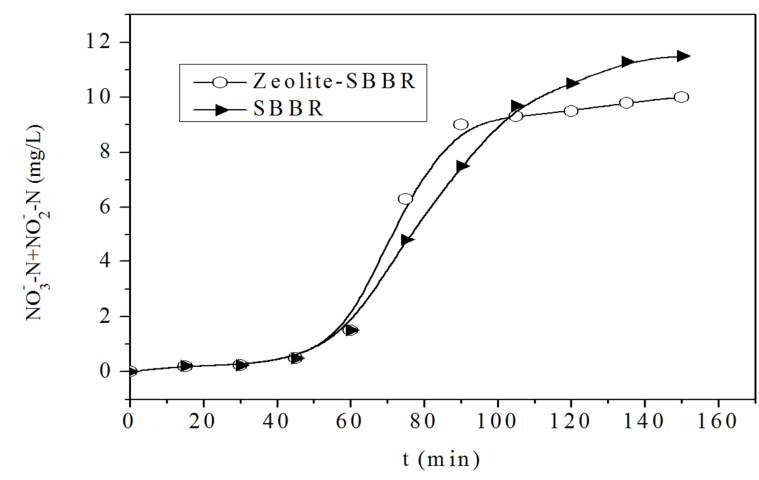

Fig. 6. Nitrate and nitrite(nitrite+nitrate) profiles for one cycle.

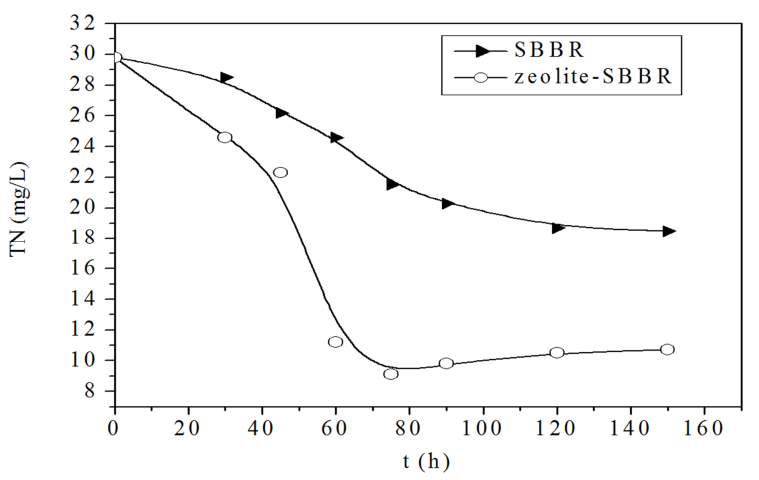

Fig. 7. TN profiles for one cycle.

For Z-S reactor, the amount of (nitrite + nitrate) increased from $0 \mathrm{mg} / \mathrm{L}$ to $9.3 \mathrm{mg} / \mathrm{L}$ in $90 \mathrm{~min}$ and then kept almost stable, while for $\mathrm{Z}$ reactor, the amount of (nitrite + nitrate) increased from $1.6 \mathrm{mg} / \mathrm{L}$ to $9.8 \mathrm{mg} / \mathrm{L}$ during $60-100 \mathrm{~min}$, and then increased to $11.7 \mathrm{mg} / \mathrm{L}$ in the next $50 \mathrm{~min}$ (Fig. 6). Compared to $\mathrm{Z}-\mathrm{S}$ reactor, the $\mathrm{Z}$ reactor has a higher concentration of (nitrite + nitrate) left after 150 min of aeration. During the period of minute 50-120, the amount of NH4+-N reduction in $\mathrm{Z}-\mathrm{S}$ reactor is lower than that in $\mathrm{Z}$ reactor, while the amount of (nitrite + nitrate) increased in Z-S reactor is more than that increased in $\mathrm{Z}$ reactor, and this verified that the nitrification rate is faster in $\mathrm{Z}-\mathrm{S}$ reactor.

It can be seen from Fig. 7 that $\mathrm{TN}$ decreased from $30.1 \mathrm{mg} / \mathrm{L}$ to $18.6 \mathrm{mg} / \mathrm{L}$ in 150 minin Zreactor, while in Z-Sreactor TN decreased by $9.8 \mathrm{mg} / \mathrm{L}$ which is about equivalent to the amount of $\mathrm{NH}_{4}{ }^{+}-\mathrm{N}$ reduction in the first $30 \mathrm{~min}$, and then $\mathrm{TN}$ was reduced to $9.3 \mathrm{mg} / \mathrm{L}$ at the aeration time point of $80 \mathrm{~min}$. During the period of $80-150 \mathrm{~min}$, it was found that the TN rose to $10.1 \mathrm{mg} / \mathrm{L}$ with the extension of aeration, and the amount of (nitrate+nitrite) was detected to have arise, whereas, it was found there was no $\mathrm{NH}_{4}^{+}-\mathrm{N}$ left in the reactor; therefore, it can be concluded that the $\mathrm{NH}_{4}{ }^{+}-\mathrm{N}$ adsorbed by zeolite powder was nitrified by nitrobacteria. Compared to the Zreactor, there has a higher TN removal in Z-Sreactor, which should be attributed to the enhanced simultaneous nitrification and denitrification (SND) took place in Z-S reactor. For the addition of zeolite powder is helpful to the formation of granular sludge with characteristics of bigger size [23, 24], which created an appropriate environment for SND.

\section{Conclusions}

Two types of operation means "SBBR reactor alone" "adding zeolite powder into SBBR reactor" were used to treat municipal wastewater, and the results obtained are as follows:

(1) The addition of zeolite powder could improve the activity of the activated sludge in SBR reactor, the SOURs of the tested sludge were enhanced significantly, and COD, $\mathrm{NH}_{4}{ }^{+}-\mathrm{N}, \mathrm{TN}$ and TP could be removed in a shorter cycle time.

(2) The addition of zeolite powder could also improve the nitrification rate and settling property of activated sludge, which is helpful to inhabit the sludge bulking 
and to enhance the performance of biological nitrogen removal.

(3) Through long-term parallel shock loadtest, it was found that the addition of zeolite powder could enhance the ability of activated sludge inresisting the shock load of organics and ammonium.

\section{Acknowledgements}

We are grateful for the open fund for Key Laboratory of Eco-Environment-Related Polymer Materials (KF-13-02) and the scientific research innovation fund for principal of Lan Zhou City University in 2014 (LZCU-XZ2014-11).

\section{References}

[1] Nguyen, M., and Tanner, C. (1998). Ammonium removal from wastewaters using natural New Zealand zeolites, N. Z. J. Agric. Res., $41,427.7$.

[2] Hai Ming, et al., (2010). Ammonium removal from aqueous solutions by using natural Chinese (Chende) zeolite as adsorbent, J Hazard Mater, 175, 247.

[3] Azhar Abdul, et al. (2010). Comparison study of ammonia and COD adsorption on zeolite, activated carbon and composite materials in landfill leachate treatment, Desalination, 262, 31.

[4] Zhu, L., and Jin Ren, N. (2009). Improving the ammonium ion uptake onto natural zeolite by using an integrated modification process, J Hazard Mater, 166,52.

[5] Seong Hoon, et al. (2004). The optimumo perational condition of membrane bio reactor (MBR): cost estimation of aeration and sludge treatment, Water Res, 38, 37.

[6] Ying Chih, et al. (2007). Control of carbon and ammonium ratio for simultaneous nitrification and denitrification in a sequencing batch bioreactor, Int Biodeter Biodegr, 59, 1.

[7] Bernardino, et al. (2011). Biofilms tratification during simultaneous nitrification and denitrification (SND) atabiocathode, Bioresource Technol, 102, 334.

[8] Yan Chen, et al. (2010). Study of operational conditions of simultaneous nitrification and denitrification in a Carrousel oxidation ditch ford omestic wastewater treatment, Bioresource Technol, 101, 901.

[9] Bernardino, et al. (2010). Simultaneous nitrification, denitrification and carbon removal in microbial fuel cells, Water Res, 44, 2970.
[10] Ping Yun, et al. (1997). Hydrothermal syntheses and structural characterization of zeolite analogue compounds based on cobalt phosphate, Nature, 388, 735.

[11] Komarowski, S., and Yu, Q. (1997). Ammoniumion removal from wastewater using Australian natural zeolite: batch equilibrium and kinetic studies, Environ. Technol, 18, 1085.

[12] Shao Bin, et al. (2006). Physical and chemical regeneration of zeolitic adsorbents for dye removal in wastewater treatment, Chemosphere, 65, 82 .

[13] Timothy, M., and James, E. (1999). Thermophilic aerobic biological wastewater treatment, Water Res, 33, 895.

[14] Adriano, et al. (2005). Removal of pharmaceuticals and fragrances in biological wastewater treatment, Water Res, 39, 3139 .

[15] Guo Ping, et al. (2010). Extracellular polymeric substances (EPS) of microbial aggregates in biological wastewater treatment systems: Areview, Biotechnol Adv, 28, 882.

[16] Susse Kirkelund, et al. (2007). Evolution of species interaction sina biofilm community, Nature, 445, 533 .

[17] Lin Chen, et al. (2008). Study on preparation and properties of activated carbon fiber/polyurethane composite carriers, Chemistry, 9, 679.

[18] Germán, B., and Iván Moreno, A. (2011). Biodegradation kinetics of a mixture of phenolsina sequencing batch moving bed biofilm reactor under starvation and shock loads, $J$ CHEM TECHNOL BIOT, 86, 669.

[19] Robinson S. M., Arnold W. D., Byers C. H. (1994). Mass-transfer mechanisms for zeolite ionexchange in wastewater treatment, AIChEJ, 40, 2045.

[20] Kara, et al. (2003). Adsorption of cobalt from aqueous solutions onto sepiolite, Water Res, 37, 224.

[21] Peng, et al. (2008). Assessing the effectiveness of treating coking effluents using anaerobic and aerobic biofilms, Process Biochem, 43, 229.

[22] Lin Chen, et al. (2008). Immobilization of Micro-Organismon Macroporous Polyurethane Carriers, Environ Eng Sci, 25, 1235.

[23] Sheng Bin, et al. (2007). Improving the performance of sequencing batchreactor (SBR) by the addition of zeolite powder, J Hazard Mater, 142, 493.

[24] Silvio, et al. (2012). Application of natural zeolites in anaerobic digestion processes: Areview, Appl Clay Sci, 58, 125. 